\title{
Os lugares do diferente no trabalho contemporâneo: trajetórias de pessoas $\mathrm{LGBTs}^{1}$
}

\author{
Rafael Paulino Juliani ${ }^{2}$ e Rosemeire Aparecida Scopinho ${ }^{3}$ \\ Universidade Federal de São Carlos (São Carlos, SP, Brasil)
}

\begin{abstract}
O artigo analisa as vivências de um grupo de trabalhadores LGBTs que visivelmente destoam dos padrões heteronormativos, para compreender as suas percepções sobre o mercado de trabalho, as formas definidas para lidar com as adversidades e os significados que atribuem ao trabalho. A sociedade contemporânea, hegemonicamente heteronormativa, conservadora e neoliberal, marginaliza as pessoas LGBTs nos diversos âmbitos da vida social, especialmente no trabalho. As identidades sexuais e de gênero são construções históricas, culturais e performativas que as transformações políticas e econômicas procuram negar ao reafirmarem a existência de uma matriz heterossexual que regula as sexualidades e a constituição dos sujeitos considerados aptos para o mundo do trabalho. Porém, para o grupo entrevistado, trabalhar, além de garantir a reprodução social, é tanto viver constrangimentos, sofrimentos e preconceitos quanto, por meio da luta cotidiana, aprender a superar barreiras, autoafirmar identidades e expressões de gênero, experimentar o reconhecimento e o exercício da cidadania, o que significa um esforço adicional pela sobrevivência.
\end{abstract}

Palavras-chave: Trabalho e diversidade social, Neoliberalismo, Precariedade, Trabalhadores Lgbts, Exclusão-inclusão precária.

The places of the different in contemporary work: work trajectories of LGBT people

This paper analyzes the experiences of a group of LGBT workers who visibly do not comply with heteronormative standards, in order to understand their perceptions about the labor market, the ways they use to deal with adversities and the meanings they attribute to work. In contemporary society, which is hegemonically heteronormative, conservative and neoliberal, LGBT people are marginalized in different areas of social life, especially at work. Sexual and gender identities are understood as historical, cultural and performance constructs that political and economic transformations have tried to deny by reaffirming the existence of a heterosexual matrix that regulates sexualities and the constitution of subjects considered apt for the job. However, for the interviewed group, working, in addition to guaranteeing social reproduction, means both experiencing constraints, suffering and prejudices and, through daily struggle, learning to overcome barriers, self-affirming identities and expressions of gender, experiencing the recognition and the exercise of citizenship, which translates to an additional effort for survival.

Keywords: Work and social diversity, Neoliberalism, Precariousness, Lgbt workers, Precarious exclusion-inclusion, Life and work trajectory.

\section{Introdução}

$\mathrm{O}$ objetivo deste artigo é o de analisar as vivências no mundo do trabalho de um grupo de pessoas que, visivelmente, destoam dos padrões heteronormativos por orientação sexual, identidade ou expressão de gênero em um contexto de transformações políticas e econômicas que o afetam.

Desde meados da década de 1980, o mundo do trabalho brasileiro tem enfrentado transformações estruturais importantes que alteraram a dinâmica do mercado de trabalho e trouxeram inúmeros impactos negativos para os trabalhadores. A crescente introdução de novas tecnologias de produção e de gestão - desde a automação microeletrônica até o advento da economia das plataformas -, a desregulamentação e internacionalização de certos ramos e setores da economia, a aprovação de dispositivos legais que permitiram flexibilizar as relações de trabalho e, mais recentemente, as reformas trabalhista e previdenciária têm agravado (os crônicos) problemas

2 https://orcid.org/0000-0002-5911-1026

3 https://orcid.org/0000-0002-2771-4770 
relacionados ao crescimento do desemprego estrutural e do trabalho informal. $\mathrm{O}$ acirramento da luta pela sobrevivência submete os desempregados e subempregados, nos setores privado e público, às mais diversas propostas da gestão econômica neoliberal, principalmente nos moldes do que tem sido chamado de uberização do trabalho ou economia do compartilhamento (Abílio, 2017; Fontes, 2017; Venco, 2019): crescente precarização das condições, intensificação do ritmo de trabalho e abandono das formas típicas de contratação que asseguram minimamente os direitos dos trabalhadores.

O impacto das reformas políticas e econômicas de cunho neoliberais tem comprometido seriamente a reprodução social de certos grupos. Neste contexto, encontram-se em situações ainda mais excludentes os que, para além das qualificações técnicas, não possuem as "qualidades sociais" exigidas pelo mercado de trabalho formal e/ou informal, como é o caso das pessoas LGBTs (lésbicas, gays, bissexuais e transgêneros), que têm o trabalho, ainda que precário, como elemento fundamental, senão o único, do sistema de reprodução social. O trabalho precário é produto das assimetrias de poderes presentes no campo das relações e condições de trabalho, determinadas pela introdução de novas tecnologias de produção e de modelos de organização e de gestão do trabalho que favorecem a sobrevivência das empresas no mercado em detrimento da seguridade social dos trabalhadores, os quais assumem todos os riscos das atividades laborais. Para Kalleberg (2009), o conceito de trabalho precário aplica-se tanto aos contratos formais que reduzem a estabilidade econômica e a segurança social dos trabalhadores, quanto àquele trabalho informal, sem contrato e, portanto, sem direitos trabalhistas e sociais garantidos e também ao trabalho autônomo realizado com meios de produção precários que põe em risco a saúde e a segurança de quem trabalha.

Bourdieu (1998a) e Castel \& Haroche (2001), para além da questão econômica, sustentam que a precariedade está relacionada a um modo de vida (do qual o trabalho é parte constitutiva fundamental) caracterizado por uma situação geral de escassez de recursos materiais e simbólicos, que são as condições que permitem ao sujeito viver com segurança e ser ativo no mundo. Quer dizer, o trabalho precário, pelas suas características, inviabiliza a existência e a manutenção de projetos de vida de longo prazo e cria um modo de viver que se caracteriza um constante ir e vir na busca pela sobrevivência, com consequências psicossociais danosas para os sujeitos. Para Bourdieu (1998a), a precariedade, que está em toda parte, é típica de um modo de dominação neoliberal que deixa os sujeitos em estado geral e permanente de submissão e aceitação da ordem social excludente. Este autor ainda esclarece que a insegurança objetiva relaciona-se estreitamente com a insegurança subjetiva porque a primeira não permite elaborar projetos de vida de longo prazo, o que priva os sujeitos das estruturas temporais que organizam a vida social, degradam as relações que eles estabelecem com os outros e com o mundo e afetam, direta ou indiretamente, os que com ele convivem.

Mas, como sobrevive o trabalhador LGBT no Brasil? Eles vivenciam tanto a precariedade do trabalho quanto a precariedade da própria condição de ser LGBT. Envergonhados, falamos do país que mais mata pessoas travestis e transexuais (TTs) no mundo (Transgender Europe, 2015). Principalmente a partir da segunda metade da década de 2010, as forças políticas neoliberais, hegemônicas e declaradamente ultraconservadoras e meritocráticas, têm reproduzido a dinâmica social excludente do capitalismo no interior do Estado e não têm medido esforços para desarticular os movimentos sociais e desrespeitar os direitos humanos. Ou seja, um país em que a articulação das atuais formas de expressão do neoliberalismo na economia com as da necropolítica praticadas pela ascensão das forças sociais neoconservadoras em diferentes esferas da vida política e social tem se solidificado e deixado um rastro de destruição física, social, subjetiva e simbólica. Resulta que $90 \%$ desta população encontra-se em situação de prostituição compulsória (Benevides \& Nogueira, 2020).

Porém, paradoxalmente, na contramão de um modelo econômico que exclui as pessoas LGBTs e de uma ordem social LGBTfóbica que não reconhece os direitos humanos e sociais, observa-se um crescente movimento social contra-hegemônico que procura problematizar e legitimar as formas de enfrentamento da opressão sexual e de gênero e definir políticas públicas e privadas de inclusão. 
O resultado deste movimento expressa-se na conquista de alguns dispositivos legais de proteção das pessoas LGBTs, tais como o reconhecimento da união conjugal entre homossexuais e a criminalização da homofobia e da transfobia. Também no mundo do trabalho, em alguns setores e organizações empresariais, a introdução de políticas de diversidade da força de trabalho vem ganhando espaço desde os anos 1980, ainda que com o intuito de criar imagens de responsabilidade social para garantir a competitividade empresarial (Heloani \& Silva, 2015; Saraiva \& Irigaray, 2009). No bojo da discussão sobre a inclusão de trabalhadores jovens, idosos, daqueles que possuem diferentes tipos de deficiências físico-intelectuais, de trabalhadores negros e mulheres cisgênero (Costa \& Ferreira, 2006), mais recentemente, também entraram na pauta as políticas de inclusão de trabalhadores/as ${ }^{4}$ com diferentes orientações sexuais, identidades e expressões de gênero.

Ainda que a discussão aconteça, de fato, verifica-se uma grande distância entre os discursos e as práticas empresariais. As políticas de diversidade LGBT têm menor aceitação na sociedade (Irigaray, 2008; Siqueira \& Zauli-Fellows, 2006) e, além disto, mesmo as empresas que declaram possuir uma ampla política de diversidade e respeito às diferenças, na prática, rejeitam a entrada de pessoas TTs no mercado de trabalho (Irigaray, 2010). O apoio à causa LGBT é visto pelos gestores como motivo de descrédito da empresa junto a mercado, clientes, fornecedores e parceiros, o que pode "manchar" a sua imagem (Juliani, 2013).

Percebe-se, assim, um processo de exclusão-inclusão precária destes sujeitos que, à medida que são impedidos de participar das relações formais de trabalho são compulsoriamente levados à informalidade ou mesmo à prostituição. Nas raras vezes em que estes trabalhadores transpõem as barreiras do mercado de trabalho, eles passam por situações de constrangimento, são alvos de piadas e de divulgação vexatória diante dos coletivos de trabalho, são alocados em funções tidas como próprias do gênero com o qual se identificam e em posições subalternas dentro de ramos específicos da economia (salões de beleza, por exemplo) ou ainda em postos de trabalho invisíveis em meio às linhas de produção, tais como atendentes de telemarketing ou camareiras - posto em que, em atividades desta natureza, não há contato presencial algum com os clientes (Garcia, 2007). Irigaray e Freitas (2013) mostraram que ser estigmatizado como homo ou bissexual no contexto de trabalho acarreta custos psicossociais para os trabalhadores e Irigaray (2008) mostrou que isto pode, ainda, prejudicar a ascensão profissional ou mesmo a permanência na organização. Situação que se apresenta ainda mais complexa para trabalhadores gays efeminados, lésbicas masculinizadas, travestis, mulheres e homens transexuais, já que estes são os que mais incomodam os "normais" ao denunciar e questionar, com seus corpos e vivências, a frágil certeza da normal social.

Em síntese, os estudos têm avançado na compreensão das diferentes problemáticas sociais que envolvem as pessoas LGBTs, porém, ainda há lacunas nos campos da Psicologia Social do Trabalho e da Administração, não somente quanto às formas de inserção e de gestão dos "LGBTTrabalhadores", mas, sobretudo, quanto às consequências subjetivas das formas de "inclusão-excludentes". Isso nos levou a questionar quais são os impactos da vivência da discriminação e da exclusão-inclusão precária no trabalho sobre o modo como estes sujeitos organizam as suas vidas em sociedade e que processos de subjetivação derivam deles. Como afirma Irigaray (2010), aprofundar os estudos sobre a realidade desses trabalhadores pode contribuir para ampliar o reconhecimento e a garantia dos direitos deste grupo no trabalho e na vida social, assim como favorecer a consolidação de contextos de trabalho promotores do respeito à diversidade sexual e de gênero que, de fato, contribuam para romper com os processos discriminatórios.

4 Doravante utilizaremos o substantivo trabalhador no gênero masculino para facilitar a redação e a leitura do texto, o que não significa desconsiderar as diferenças.

5 Os marcadores de sexualidade e identidade de gênero não são ignorados nos contextos de trabalho. Essas pessoas não são socialmente vistas apenas como trabalhadores, mas como "LGBTTrabalhadores", conforme denominou (Juliani, 2017). 
Partindo da exposição do percurso teórico-metodológico, na sequência, analisamos as trajetórias de trabalhadores LGBTs, procurando destacar as suas percepções sobre o mercado de trabalho, as formas definidas para enfrentar a discriminação, assim como os significados do trabalho.

\section{Diversidade sexual e de gênero e trabalho}

Partimos do pressuposto de que a sexualidade e o gênero não se limitam apenas ao âmbito do biológico e do individual. Ao contrário, o debate e o consequente controle político-social que se coloca sobre estes temas, embasados na crença de uma ordem "natural", tornam-se meio para ordenar e tornar inteligíveis as relações entre os sujeitos sociais no âmbito público. Diferentemente do que apregoa o pensamento médico-biologicista, as identidades sexuais e de gênero são aqui compreendidas, com base em Butler (2003), não como naturais e fixas, mas como processos históricos, culturais e performativos. Como alerta Arán (2006), os discursos da Sexologia, Psiquiatria e de parte da Psicanálise, que conferem um status patológico às sexualidades não heterossexuais e principalmente à transexualidade, baseiam-se no entendimento que existe uma matriz heterossexual binária reguladora das sexualidades e da constituição dos sujeitos.

O processo de naturalização das identidades de gênero e a patologização daqueles que fogem da norma estabelecida produzem as margens, local habitado pelos seres abjetos, a quem se destinam as sentenças pelo descumprimento da norma. Como argumenta Rubin (2003), a organização da sexualidade em sistemas de poder serve para recompensar e estimular certos sujeitos sociais e para punir e reprimir outros. Assim, todos aqueles que rompem com os padrões heteronormativos na expressão de sexualidade e com a binaridade de gênero (masculino/feminino) na relação com o corpo são socialmente penalizados por causarem estranhamento aos demais. Os seus "defeitos", seus marcadores sociais de diferenças, ganham peso considerável nas suas trajetórias e no modo de ganhar a vida. Por não gozarem do status de sujeito e habitarem o inabitável (Butler, 2003), a eles restam os trabalhos socialmente menos reconhecidos.

Porém, Dubar (2012) afirma que todos os tipos de trabalhos possibilitam um espaço de socialização que, para além da acumulação de conhecimentos profissionais, permite a incorporação de uma autodefinição e projeção para o futuro. Também para este autor, a pertença a um coletivo de trabalho, um dos direitos modernos mais fundamentais, conduz ao aprendizado e engajamento subjetivo, o que permite ao trabalhador pensar o seu futuro. "Situar assim o trabalho no centro da vida social e das existências individuais constitui uma característica essencial da modernidade que nenhuma profecia sobre 'o fim do trabalho' conseguiu destruir" (Dubar, 2012, p. 14). Neste sentido, o mundo do trabalho, indissociável à construção subjetiva em nossa cultura, ainda é um ponto de referência fundamental para os processos de subjetivação contemporâneos, bem como um importante fator que orienta a dinâmica das sociedades capitalistas devido às complexas relações que se forjam no encontro (ou desencontro) do sujeito com a atividade laboral. Para além do econômico e do material, o trabalho continua estruturante das relações sociais (e estruturado por elas), tanto no que se refere à pertença, institucional e comunitária, quanto na construção dos valores culturais e morais, além de possibilitar a convivência com "os outros", outras vidas repletas de significados sociais (Sennett, 2009).

Nardi (2003) alerta que o valor moral atribuído ao trabalho só existe devido à sua incorporação como valor simbólico que o transformou em elemento central na constituição do tecido social. Se, como argumenta este autor, o trabalho inscreve o trabalhador na lógica protetora do Estado e lhe assegura o exercício dos direitos sociais, ocorre que, atualmente, este mesmo Estado que, em alguma medida, discursava sobre a proteção dos trabalhadores frente aos abusos do capital privado, incorporou declaradamente a lógica capitalista mediante um duplo movimento. 
Segundo Fontes (2017), por um lado, o movimento consiste em reduzir a intervenção na reprodução da força de trabalho empregada (alargando a massa de desempregados) e prepará-la para subordinarse diretamente ao capital. Por outro lado, impõe como necessárias e inevitáveis as exigências do capital aos trabalhadores, por exemplo, por meio da superposição de formações profissionais adequadas às demandas do mercado, bem como pelo forte incentivo a desenvolver o espírito empreendedor, para que eles se disponham ao trabalho independentemente de haver relações contratuais e demais direitos. Neste sentido, Pierre Dardot e Christian Laval (2015), afirmam que o Estado neoliberal tem papel fundamental na extensão da lógica do mercado para outras esferas da vida social:

O Estado neoliberal é "governamentalizado", no sentido de que os novos dispositivos institucionais que o distinguem visam criar situações de concorrência, introduzir lógicas de escolha, desenvolver medidas de desempenho, cujo efeito é modificar a conduta dos indivíduos, mudar sua relação com as instituições e, mais precisamente, transformá-los em consumidores e empreendedores. As políticas educacionais e acadêmicas são exemplos perfeitos dessa dinâmica (Dardot \& Laval, 2015, p. 288).

Dardot e Laval (2016, p. 16) argumentam que a racionalidade neoliberal vai além da "destruição programada das regulações e das instituições". Além da retirada de direitos, o que está em questão é a produção de certo tipo de relação social, de maneiras de viver e de certas subjetividades regidas pela competição generalizada, em que a lógica do mercado é internalizada e o sujeito passa a ser e a se comportar como empresa, o "homem empresarial", subjetivamente oposto àquele que respeita o "princípio do bem comum". Assim, a presente configuração social e do mundo do trabalho, suas formas de produção e de consumo, permeados pelos processos de precarização, de flexibilizações de contratos e direitos, de exigências técnicas e sociais, geram inúmeras incertezas e barreiras quase intransponíveis para a maioria dos trabalhadores "normais", especialmente, para os LGBTs, cujo lugar, desde sempre, tem sido a margem.

\section{Trajetórias de trabalho e o mercado de trabalho formal}

Este artigo deriva de uma pesquisa cujo objetivo foi conhecer as vivências dos trabalhadores LGBTs no mundo do trabalho (Juliani, 2017). Nesta pesquisa, utilizando a noção de trajetória de vida de Bourdieu (1998b) - conjunto de acontecimentos sucessivos na vida de um sujeito que possui relação sequencial e inteligível, à medida que transcorre cronológica e logicamente, e informa sobre os seus caminhos, as suas escolhas e, sobretudo, a sua posição na estrutura social - todos os momentos da vida dos entrevistados foram revisitados, desde as relações com a família e a escola até as diferentes experiências de trabalho, o que contribuiu para entender a posição que eles ocupavam no mundo laboral no momento da pesquisa. Com base na técnica de referências em cadeia Snowball (Goodman, 1961), contatamos pessoas LGBTs, principalmente travestis e transexuais que faziam parte da rede de contatos de organizações não governamentais (ONGS) pró-direitos LGBT, do interior do Estado de São Paulo, via rede social Facebook. A mensagem enviada aos possíveis participantes apresentava a pesquisa (seus objetivos e expectativas quanto à aplicação dos resultados), bem como verificava se eles possuíam experiências de trabalho. Assim, selecionamos intencionalmente sete trabalhadores em função das suas orientações, identidades e expressões de gênero destoantes dos padrões heteronormativos e das suas experiências de trabalho. Desenvolvemos e utilizamos um roteiro semiestruturado para o levantamento de informações junto aos entrevistados, que tinha como eixos norteadores: a) seus dados pessoais; b) trajetória escolar; c) formação profissional; d) ivência de discriminações na trajetória de trabalho; e e) expectativas e planos futuros. 
Visando reconstruir as suas trajetórias, foram realizadas tantas entrevistas ${ }^{6}$ quanto foram necessárias com cada um dos entrevistados. Os encontros ocorreram individualmente em um shopping center, em uma ONG, na casa de uma das entrevistadas e nos locais de trabalho de quatro delas. Os espaços para a realização das entrevistas foram indicados pelos próprios sujeitos, que assinaram um Termo de Consentimento Livre e Esclarecido antes da realização e gravação das conversas em áudio com o pesquisador. As entrevistas desenrolaram-se informalmente, como longos bate-papos, algumas vezes acompanhados de bolos ou biscoitos que o entrevistador levava para os encontros. A produção discursiva obtida foi processada com base na análise temática de conteúdos proposta por Minayo (1999).

Neste artigo, trataremos especificamente da análise das trajetórias de trabalho, onde desaguavam as principais consequências das vivências de discriminações dos entrevistados que, além da condição de ser LGBT, ressentiam a falta de preparação emocional, escolar e profissional para enfrentar os desafios do trabalho e da vida adulta, como se, ao invés de vítimas, fossem culpados pela exclusão vivenciada. Serão aqui apresentados os trechos mais emblemáticos das suas falas, referentes aos temas da formação profissional, vivência de discriminações na trajetória de trabalho, expectativas e planos futuros, extraídas das entrevistas realizadas por Juliani (2017). O Quadro 1 identifica os entrevistados com nomes fictícios e sintetiza algumas de suas características.

Quadro 1: Autoidentificação dos entrevistados por idade, trabalho atual, orientação sexual, identidade de gênero e expressão de gênero

\begin{tabular}{|c|c|c|c|c|c|}
\hline Entrevistado & Idade (anos) & Trabalho Atual & Orientação Sexual & Identidade de Gênero & Expressão de Gênero \\
\hline Raquel & 30 & Professora de Dança & Homossexual & Transex & Feminina \\
\hline Anderson & 43 & Segurança & Heterossexual & Homem trans & Masculina \\
\hline Bárbara & 37 & Esteticista & Homossexual & Transgênero & Feminina \\
\hline Valentina & 42 & Enfermeira & Homossexual & Travesti & Feminina \\
\hline Letícia & 40 & Tapeceira & Homossexual & Mulher cisgênero & Masculina \\
\hline Yara & 31 & Prostituta & Homossexual & Travesti & Feminina \\
\hline Aurora & 45 & Cabelereira & Heterossexual & Mulher trans & Feminina \\
\hline
\end{tabular}

Fonte: Trabalho de campo realizado entre 2015 e 2016.

Os entrevistados possuíam variadas autoidentificações quanto às suas identidades e expressões de gênero ${ }^{7}$, o que evidenciava uma ruptura com a lógica biologicista e heteronormativa socialmente posta. Ressalta-se que as narrativas obtidas não representam todos os tipos de pessoas LGBTs. Mesmo dentro de cada um dos subgrupos que formam o grupo entrevistado, foram percebidas inúmeras histórias e posicionamentos que dependiam das circunstâncias de vida de cada um.

Eles iniciaram-se no mundo do trabalho entre os dez e dezesseis anos, motivados pela necessidade de auxiliar nas despesas domésticas, de manterem-se longe das famílias porque foram expulsos de casa na época da revelação, e/ou pelo desejo de consumo (comprar "brinquedos de meninas", como relatou Aurora). Embora constem no Quadro 1 apenas as atividades exercidas no momento das entrevistas, os trabalhadores relataram experiências de trabalho muito diversas umas das outras, desde a prostituição e diferentes tipos de trabalhos informais, como a realização de "bico", até o trabalho formal em empresas privadas e no setor público em cargo concursado, entre outros. Informaram ter renda mensal suficiente para a manutenção básica de si mesmos e de suas famílias, sem grandes extravagâncias e com muito planejamento financeiro, ou seja, dependiam,

6 Mediante aprovação do Comitê de Ética de Pesquisa com Seres Humanos, de acordo com Resolução 466/12 do Conselho Nacional de Saúde.

7 A identidade de gênero diz respeito à forma como a pessoa compreende o seu gênero, que pode ou não concordar com o seu sexo biológico (aparelho reprodutivo); a expressão de gênero é a maneira como a pessoa apresenta-se e informa, socialmente, o gênero de pertencimento. 
estritamente, do trabalho para sobreviver e, na ausência dele, contavam com a solidariedade familiar e dos amigos.

No momento das entrevistas, seis deles exerciam atividades laborais remuneradas (apenas Anderson encontrava-se afastado por motivos de saúde), o que evidencia que, em alguma medida, eles conseguiram ter acesso ao mercado de trabalho, formal ou informal. Entretanto, não alcançaram isto sem experimentarem barreiras, constrangimentos, preconceitos (explícitos e velados), boicotes e outras formas de violências simbólicas. Entre os fatores que podem facilitar ou dificultar a entrada e permanência das pessoas LGBTs no mercado formal de trabalho, o mais citado foi a "passabilidade", noção que se refere à adequação comportamental, física e/ou jurídica que o sujeito deve fazer para que a sua orientação sexual e, principalmente, a sua identidade transgênero não sejam questionadas ou constituam barreiras para "passar", ou seja, acessar e pertencer aos espaços sociais. Conforme destacado por Duque (2013), "para passar por", o corpo dissidente reveste-se, de modo a não se destacar e não ser percebido como diferente. Principalmente a aparência física é uma barreira, não apenas para a entrada, mas também para a permanência no trabalho formal. Isto vai ao encontro das ideias de Butler (2003), Pereira (2012) e Veras e Guasch (2015) ao demonstrarem que romper com o binarismo de gênero por meio da vivência dos corpos TTs causa estranhamento e incômodo à sociedade, mais evidentes em contextos marcados por uma suposta moral e pelo conservadorismo, como os do trabalho formal.

A forma discreta e polida com que a pessoa LGBT porta-se pode ser garantia para a aceitação e permanência no trabalho. Bárbara, por exemplo, utilizou-se dos benefícios desta invisibilidade nos lugares onde trabalhou: "Mas, eu sempre fui mais contida, sempre tive uma postura mais delicada, mais discreta e por isso eu acho que você acaba sendo mais confundida, passa batido melhor como mulher, não chama atenção". Para Aurora, a camuflagem mais relevante referia-se à imagem corporal. Aquelas pessoas trans que possuem uma imagem mais próxima ao padrão ideal dos corpos femininos e masculinos adquirem certa invisibilidade que mascara os seus "defeitos sociais". Anderson referiu que, a partir do momento em que começou a fazer uso de hormônios para desenvolver características mais masculinas, como a barba, algumas relações tornaram-se mais fáceis.

Estas falas foram consonantes com o que dizem Pereira (2012) e Bento (2011) sobre o estranhamento que os corpos causam e a consequente exclusão destes que transitam entre os extremos (masculino e feminino) do gênero. Deste modo, tornar-se invisível, também no trabalho, é a palavra de ordem para travestis, mulheres e homens trans que não devem ter corpos indecisos, "em cima do muro". O ideal é que se posicionem como homem ou como mulher, porém de modo muito sutil, subserviente e respeitoso, conforme recomenda a boa moral e os bons costumes, porque é a divisão técnica e social do trabalho baseada no referido binarismo que tem sustentado a ordem produtiva vigente. Situação que, nos modos precários de trabalho, intensifica as desigualdades de gênero (Kalleberg, 2009), mesmo para pessoas cisgêneras, quanto mais para as pessoas transgênero.

Entretanto, Aurora disse que de nada adiantava possuir uma imagem condizente com os padrões sociais se houvesse incongruência entre os aspectos físico e jurídico. Segundo a entrevistada:

Antes, mesmo as pessoas me vendo de tailleur, de joias, maravilhosa, eu era chamada de senhor. Agora [após ter feito as alterações cirúrgicas e jurídicas de gênero] eu posso colocar um terno, apresentar um RG de mulher, eu sou chamada de senhora! (Aurora - mulher transexual, cabeleireira)

De fato, apesar dos avanços jurídicos quanto ao direito de uso do nome social, algumas instituições permanecem conservadoras, ignoram e desrespeitam as identidades trans.

De forma geral, assim como aponta Irigaray (2008), para os entrevistados o cada vez mais seletivo mercado de trabalho formal incorpora pessoas LGBTs, desde que elas possuam corpos e comportamentos padronizados: homens gays discretos, que "deem pouca pinta"; mulheres lésbicas 
femininas e mulheres e homens transexuais que de fato se pareçam com homens e mulheres "reais". As travestis não configurariam este grupo, pois todos os entrevistados afirmavam que elas sempre são associadas ao "mercado do sexo" e, por esta razão, são discriminadas. Segundo Bárbara: "Ainda tem essa imagem [de que] o lugar dela [da travesti] ainda é na esquina, ainda é na prostituição, ainda é aquele estereótipo de violenta, de coisas assim, bem ruins". Para Letícia: "O gay e a lésbica estão mais maquiados. Quando você é trans e vai trabalhar você é um homem vestido como mulher. A imagem é mais forte, desagrada mais os olhos".

As falas condizem com Veras e Guasch (2015) ao mostrarem que mesmo a imprensa brasileira tem auxiliado na construção enviesada da imagem da travesti como prostituta, marginal, viciosa. Ao que parece, a afirmação de Green (2000) de que, nos anos 1960, o termo travesti era sinônimo de pessoa que se prostituía, persiste até os dias de hoje, inclusive no mundo do trabalho, como verificou Irigaray (2010). A associação acontece porque, no pensamento comum, as prostitutas e as travestis são vistas como desviantes ou pervertidas, estão fora dos padrões típicos da sociedade.

Rubin (2003), com a alusão àquilo que chama de Pirâmide Erótica, demonstra os negativos impactos nas mobilidades sociais e econômicas para aqueles que se afastam do ideal do comportamento social. Desta maneira, a sociedade legitima e reforça a compreensão de que aos "sujeitos das margens" cabem os trabalhos também marginais. Trabalhos informais, invisíveis e precários se traduzem em instabilidade e incerteza econômica e social para os sujeitos, com reflexos em outros âmbitos da vida: físico, psicológico, da vida em comunidade. "Já que o trabalho está intimamente ligado a outros eventos sociais, econômicos e políticos, o crescimento do trabalho precário e da insegurança também teve efeitos extensos em fenômenos relacionados ou não ao trabalho" (Kalleberg, 2009, p. 24).

\section{As vivências de discriminações e as formas de enfrentamento}

As experiências de discriminação vivenciadas nos contextos de trabalho formal e informal levavam os entrevistados, constantemente, a valerem-se de distintos modos de enfrentamento para ali permanecerem. Valentina relatou que, no setor público, as relações também não eram tão mais estáveis e cordiais como se poderia imaginar quando se tratava de trabalhadoras travestis. Ela contou que um assessor de saúde mandou que cortasse os seus longos cabelos. Ela negou-se: "Eu entrei através de um concurso, eu não entrei pela porta dos fundos da prefeitura". A fala mostra que o fato de a entrevistada ter conseguido o emprego por meio de um concurso público, processo formal com garantias legais, era utilizado como forma de enfrentar as situações de violação dos seus direitos como trabalhadora.

Principalmente quando desenvolvem trabalhos precários, os trabalhadores LGBTs vivenciam situações em que são postos à prova os seus conhecimentos, as suas habilidades relacionais e técnicas e os seus desejos concretos de estarem naquele local. Anderson mencionou que foi boicotado pelos seus superiores e colegas de trabalho. Na loja de artigos esportivos em que trabalhou como vendedor comissionado era escalado para fazer serviços de limpeza para evitar que atendesse os clientes. Diante disso, desdobrava-se para "mostrar serviço" e garantir tanto o salário quanto o emprego em si: "tentava me destacar de alguma forma para ficar, para que ninguém visse como se [ser trans] fosse um defeito, não é?".

Soma-se às características da precarização do trabalho no regime neoliberal a ausência de políticas e práticas organizacionais de proteção e respeito aos trabalhadores LGBTs, razão pela qual ocorrem situações abusivas, como as relatadas pelos entrevistados. $\mathrm{O}$ que deveria ser um direito do trabalhador torna-se benevolência e favorece a prática de chantagens e outras formas de relações perversas no trabalho. A ausência dessas políticas e práticas leva os trabalhadores 
LGBTs a realizar esforços extras que em nada se relacionam com as atividades laborais na tentativa de manterem os seus empregos, o que pode acarretar custos emocionais e físicos adicionais para além dos que são inerentes ao trabalho no qual foi possível encaixarem-se ao longo de suas trajetórias. Anderson relatou situações de desentendimentos ocorridas, nas quais o seu "defeito" foi utilizado como argumento principal para questionar o seu profissionalismo, o que culminou em tentativas de suicídio:

Isso dá vontade de você tomar veneno! Eu tomei três vezes. Porque eu ia trabalhar, tinha sempre alguém que falava: "Ô, sapatão! Pega pão lá para mim”. Isso na frente de todo mundo.... Quer dizer, eu nunca fui funcionário, eu nunca fui a pessoa, o vendedor, nada. Eu fui: Sapatão! . . Então isso me levou a tomar, a [tentar] acabar com minha vida três vezes. Dei sorte de não morrer (Anderson homem transexual, segurança).

Como apontam Irigaray e Freitas (2013), são inúmeros os custos psicossociais para aqueles trabalhadores LGBTs que sofrem violações e discriminações no trabalho. Tais situações, não raramente, acarretam falta de motivação, estados depressivos e, em casos mais severos, tentativas recorrentes de suicídio, evidência clara das consequências psicossociais danosas referidas por Bourdieu (1998a), as quais deixam o sujeito privado da convivência social que organizam as relações e fundamentam projetos de vida.

\section{Experiências e opiniões sobre a prostituição}

Kalleberg (2009) aponta que a precariedade no trabalho formal se evidencia, entre outros fatores, pela perda de contratos e direitos básicos do trabalhador. Na economia informal, fora da regulação do Estado, a precariedade expressa-se na atuação de pessoas relativamente inexperientes, que realizam vendas como ambulantes ou combinam várias atividades simultaneamente e oferecem todo o tipo de serviço pessoal.

A prostituição talvez seja o tipo de "serviço" pessoal mais perigoso e insalubre dentre as atividades precárias. Diante da dificuldade de acessar o mercado de trabalho formal e informal, inclusive pela carência de preparo educacional e técnico (Junqueira, 2012), as pessoas transgênero, principalmente travestis e mulheres trans, recorrem majoritariamente à prática da prostituição para sobreviver. No ano de 2019, 90\% das pessoas TTs desempenhavam esta atividade (Benevides \& Nogueira, 2020), o que evidencia uma prostituição compulsória desta população e não uma simples escolha de meio para ganhar a vida. Vale lembrar o alto número de assassinatos de pessoas TTs (Transgender Europe, 2015), bem como a baixa expectativa de vida destas pessoas no Brasil aproximadamente, 35 anos (Benevides \& Nogueira, 2020).

Aurora relatou diversos eventos em que teve de se valer de seringas falsas, cheias de molho de tomate, para fugir de clientes agressivos, dizendo que se tratava de sangue com o vírus HIV. Yara, entretanto, ignorando os riscos inerentes à prostituição nas ruas, disse não ter sofrido quaisquer violências ou discriminações em sua trajetória como prostituta. No entanto, à medida que contava as suas histórias, ficou evidente a negação dos acontecimentos. Ela contou sobre uma colega de ponto que foi perseguida e atacada por dois garotos com um taco de baseball. Porém, Yara não reconhecia que tais violências também fossem direcionadas a ela. Aparentemente, não reconhecer ou não querer lidar, diretamente, com as externalizações do preconceito é uma forma utilizada pelas travestis que se prostituem para sobreviverem e permanecerem nas esquinas.

Para além dos riscos à saúde e à vida, a prostituição pode trazer impactos significativos sobre a imagem da pessoa TT, os seus relacionamentos sociais e a execução das demais atividades do cotidiano. 
Bárbara informou que, por ficar a noite toda "para o crime" nas praças de sua cidade, não conseguia desenvolver nenhuma outra atividade durante o dia; outro trabalho, por exemplo. Não apenas pelo cansaço físico decorrente do trabalho "na noite", mas também por vergonha de ser o que é: "Sabe quando você vai ficando um zumbi? Parece que você não tem contato, não quer ter contato, tem vergonha de ter contato com as pessoas do dia".

A fala de Bárbara vai ao encontro do que diz Bento (2011) sobre os sujeitos que fogem da norma e que, por esta razão, são empurrados às margens, tornando-se "mortos vivos sociais". Para Saraiva (2012), os que estão em desacordo com as normas sociais são colocados na invisibilidade por um processo de diferenças que produz uma redução ou nulificação das possibilidades de interlocução com a sociedade.

Entretanto, apesar destes relatos e diante das experiências frustradas de busca por trabalho formal e da vivência de discriminações em trabalhos anteriores, a prostituição foi tida como algo vantajoso pelas entrevistadas Yara e Aurora, visto que tinham flexibilidade para definir quando e como trabalhar, ou seja, livres das ordens de patrão.

As entrevistadas demonstravam aquilo que Dardot e Laval (2016) chamam de naturalização das regras do jogo neoliberal, pois, diante das dificuldades de inserção no mercado de trabalho formal e da falta de garantias mínimas de seguridade e de direitos, elas incorporavam o "espírito do empreendedorismo", enxergando a si próprias como "sujeitos empreendedores de si" ao verem vantagens e meritocracias até mesmo na forma mais precária da informalidade.

\section{As dores e as delícias de ser LGBTTrabalhador: para que serve o trabalho?}

O trabalho foi compreendido de modos diversos, contraditórios ou mesmo compensatórios pelos entrevistados. Para eles, o trabalho era responsável por tornar as pessoas "mais dignas". Isto por ser o trabalho um marcador social que distingue e classifica os sujeitos, normalmente, sob signos que expressam grande desprezo por aqueles que são vistos como socialmente inativos/"vagabundos". Como aponta Jodelet (2005) ao tratar do conceito de alteridade, "os outros" somente podem ter garantia de inserção e participação social quando os "cidadãos normais" lhes atribuem características e valores socialmente reconhecidos como positivos.

Não somente as atividades formais foram acrescidas de valor simbólico pelos entrevistados. Qualquer tipo de trabalho "enobrece o homem em amplos sentidos", segundo Letícia, para quem o trabalho, de forma geral, atravessa e é atravessado por relações sociais de interdependências e possui uma dimensão simbólica relacionada ao reconhecimento social e à realização de si. Isto condiz com a hipótese defendida por Dubar (2012) para quem, diferentemente do que versa a sociologia funcionalista, todas as atividades de trabalho (não apenas as ditas "profissionais") são reconhecidas como meios para a socialização, construção de si e reconhecimento social. O processo de socialização profissional, como afirma este autor, é algo bastante geral que se constrói permanentemente e conecta situações e percursos, tarefas a realizar e perspectivas a seguir, relações com outros e consigo mesmo. Processo pelo qual se estruturam os mundos do trabalho e se definem os sujeitos pelo trabalho que realizam. Como apontou Valentina: “... hoje eu entro e saio de qualquer lugar, mas têm amigas minhas que não conhecem um shopping, entendeu?".

Embora, ideologicamente, os sujeitos naturalizassem e aceitassem as regras do jogo neoliberal (Dardot \& Laval, 2016) considerando o trabalho como forma de "enobrecer", porque não visualizavam saídas possíveis para a exploração e a exclusão. Ao mesmo tempo, também o concebiam como um espaço intersubjetivo fundamental para a construção de representações de si, meio de pertença social como coloca Dubar (2012), conforme exemplificado pelo trecho da fala de Bárbara: 
Você se sente útil para alguma coisa. Parece que você serve para alguma coisa, sabe? Que até então, você sempre se sente a escória da sociedade, não é? ... Então você vê que, realmente, tem o seu jeito de ser, tem as suas qualidades, os defeitos, mas você pode acrescentar também à sociedade (Bárbara transgênero, esteticista).

Assim, revelavam-se as contradições intrínsecas das relações de trabalho contemporâneo, as suas dores e delícias. Anderson, apontando para a mesma questão, também entendia o trabalho como uma necessidade/obrigação, como local de constrangimentos, humilhação, desespero, luta, provação de valores socialmente reconhecidos, mas também como local para superar obstáculos, obter realização profissional e validar direitos conquistados. O trabalho contribuiu para ressignificar e construir novas possibilidades para a sua vida porque também lhe serviu para reforçar a sua masculinidade, à medida que alguns superiores e colegas o chamavam pelo pronome masculino "de uma forma mais firme, como um homem mesmo", e também quando conseguiu assumir cargos tipicamente masculinos, que o auxiliaram a performar e a construir o gênero com o qual se identificava. Como mostra Salvagni (2011), os modos de trabalhar podem impactar, significativamente, não apenas nas identidades profissionais, mas também nas próprias identidades de gênero, à medida que, inserido em um contexto fortemente marcado pela divisão sexual do trabalho, aquele que trabalha se reconhece mais ou menos homem ou mulher, dependendo das funções que desempenha.

De forma geral, os entrevistados não visualizavam a possibilidade de construir carreira profissional. No decorrer de suas vidas, aceitaram as poucas oportunidades e tiveram que mudar de trabalho quando se viram diante de situações insustentáveis de desrespeito e violação de direitos. No entanto, avaliaram positivamente as suas trajetórias de trabalho. Valentina, inclusive, associou o bom desenvolvimento da sua trajetória profissional com o fato de ainda estar viva: "Eu tinha uma perspectiva de vida, dentro do contexto de travesti, de 30 anos, não é? Eu vou fazer 43. Quer dizer: eu já vivi quase 15 a mais do que a minha perspectiva”. Por meio do trabalho, ainda que precário, eles não apenas garantiram a reprodução material de suas vidas, mas certa inserção social, acrescida de valor simbólico pelos outros, os "normais", que lhes permitiram participar de certas dinâmicas sociais. Porém, isto nem sempre ocorre com os que permanecem nas mais longínquas partes das margens sociais. Estes sujeitos não querem, e com razão, serem apenas tolerados e passados de forma despercebida na sociedade. Anderson deixa isto claro quando solicitou algo mais:

Eu gostaria de ter ido além. Não fui muitas das vezes porque as forças falham, falta força também para você brigar sempre, entendeu? Me acovardei em algumas coisas que podia ter lutado mais. Mas por solidão . . . Você não tinha apoio, você não tinha exigência, você não tinha nada. Então, você podia ser melhor, sim! Inclusive escola, outras coisas. Eu tive vontade de fazer vários cursos e só não fui porque, realmente, o preconceito de chegar lá e ouvir: "Não! Mas, você vai fazer curso de eletricista? Isso é para homem!". Então, se eu tivesse tido essa oportunidade, esse direito, com certeza, eu acho que eu tinha a oportunidade de buscar muito mais coisas. Não tive, realmente, por falta de apoio, mas, não é apoio de pai e mãe, de amigos, não! Apoio legal. Apoio de você ter o direito de ir ao banheiro, de pôr a roupa que você quer pôr. Eu deixei de trabalhar em lojas porque o uniforme era saia, lencinho. Eu briguei de uma forma, eu me impus de uma forma que eu usava a calça dos meninos e acabou. E foi assim em todos os meus serviços. Então, onde eu pude fazer assim eu fiz e trabalhei. Mas, a partir do momento que eu não tive esse apoio eu não consegui (Anderson - homem transexual, segurança).

A fala do entrevistado justifica e reforça a necessidade de criar efetivas práticas de gestão, baseadas em políticas organizacionais voltadas para garantir a presença e, principalmente, 
a permanência de pessoas LGBTs no trabalho. Tais práticas podem configurar o apoio que Anderson solicitou para se somarem aos esforços individuais que estes sujeitos empenham em suas trajetórias de trabalho, não raramente em situação precária, para lidar com uma sociedade que ainda hoje se choca com as diversas outras configurações do gênero e da sexualidade.

Em síntese, para os entrevistados, o mundo do trabalho é ambíguo e contraditório. Significa tanto a dor do enfrentamento das barreiras para realizarem as suas identidades sexuais e de gênero e a exigência de um esforço cotidiano adicional para reafirmarem seus potenciais de trabalho, quanto a delícia de ser uma espécie de chave que abre as portas para o reconhecimento e a autoafirmação como sujeito social "diferente". Tais representações, além de reafirmarem as desigualdades sociais que envolvem as identidades sociais relacionadas ao gênero e ao sexo, ancoram-se na típica cultura do trabalho brasileira que, apesar das mudanças, ainda está centrada no emprego formal e não no trabalho, como fonte de inserção e de segurança social (Borsoi, 2005).

Por fim, os entrevistados tinham planos para o futuro que carregavam uma grande carga política e demonstravam ser meio de autoafirmação social. Infeliz ou felizmente, estar fora da norma por ter orientação homossexual, identidade ou expressão de gênero transgênero, implica não somente existir, mas também lutar - especialmente no contexto político contemporâneo em que os poucos direitos conquistados por esta minoria social são ameaçados pela ordem social ultraconservadora que reproduz a dinâmica neoliberal e que deixa os cidadãos à mercê do capital. Eles sabiam que não poderiam simplesmente viver as suas vidas como as demais pessoas. Também precisariam incessantemente lutar pela garantia dos seus direitos, ainda lentamente reconhecidos, e resistir a uma sociedade e projeto de país que investe grandes esforços para destruí-los. Ser LGBT é (e, provavelmente, sempre será) jamais abandonar a luta pelos direitos humanos mais básicos, entre eles, o do trabalho.

\section{Considerações finais}

Foi possível perceber que os entrevistados colecionavam um conjunto de vivências de preconceitos e de exclusão em diferentes âmbitos da vida social (escolar, familiar e de trabalho) que os colocava em situação de insegurança generalizada. Especificamente o campo do trabalho tornava-se local de enquadramento dos corpos e desejos, naquilo que pode ser considerado legítimo e adequado ao mundo produtivo. Este pode ser considerado um dos impactos mais perversos da gestão neoliberal na vida desses trabalhadores porque supõe que eles tenham uma determinada identidade social para serem aceitos no mundo do trabalho - a de "homem empresarial" ou "homo agens" como dizem Dardot e Laval (2016) -, que "os corpos indecisos" jamais poderiam almejar para si.

Por outro lado, era também no trabalho, ainda que com oportunidades escassas e experiências difíceis, que eles conseguiam transpor algumas barreiras para se autoafirmarem, como gente, como sujeitos sociais, não apenas como "homem empresarial". Mesmo entre sentidos diversos, contraditórios ou mesmo compensatórios e ainda que os mantivesse nas franjas da sociedade, o trabalho possibilitava: 1) manter as suas vidas e dos que deles dependiam; 2) realizar sonhos/objetivos pessoais e familiares; 3) planejar o futuro, ressignificar a vida e desenvolver-se; 4) ser incluído, aceito, ter utilidade e distinção social; 5) ter o direito sobre o próprio corpo; 6) lidar com as frustrações pessoais e construir representações positivas de si mesmo e de performance de gênero.

Está posto o desafio de pensar em conjunto, na academia e no mundo do trabalho, políticas e práticas de gestão em duas direções: primeiramente, quanto à real inclusão de pessoas LGBTs, principalmente travestis e transexuais, visto que, majoritariamente, elas exercem atividades de prostituição no "mercado do sexo", o que evidencia as grandes barreiras postas à sua participação 
no trabalho, formal e/ou informal; em segundo lugar, é necessário dar atenção especial para as ações direcionadas à permanência dos que conseguem se inserir nos contextos de trabalho. É importante confrontar os discursos e as práticas empresariais, ditos socialmente inclusivos, para verificar em que medida eles são correspondentes, o que tem sido um desdobramento da pesquisa relatada neste artigo.

Porém, somente por meio de um projeto político-social mais amplo é que podemos enfrentar as violências e violações vivenciadas, diariamente, pelos sujeitos que estão fora das normas sociais. Caso contrário, as pessoas LGBTs, principalmente as travestis, com seus corpos perturbadores das normas da sexualidade e do gênero, permanecerão, indeterminadamente, como excessos sociais a serem violentamente combatidos e friamente eliminados para que os demais, os "normais", possam se construir como grupo coeso, como sociedade.

\section{Referências}

Abílio, L. C. (2017). Uberização do trabalho: subsunção real da viração. Passa Palavra. Recuperado de https:// passapalavra.info/2017/02/110685/

Arán, M. (2006). A transexualidade e a gramática normativa do sistema sexo-gênero. Ágora: Estudos em Teoria Psicanalítica, 9(1), 49-63.

Benevides, B. G. \& Nogueira, S. N. B. (2020). Dossiê dos assassinatos e da violência contra travestis e transexuais brasileiras em 2019. São Paulo: Expressão Popular; ANTRA; IBTE. Recuperado de https://antrabrasil.files.wordpress. com/2020/01/dossic3aa-dos-assassinatos-e-da-violc3aancia-contra-pessoas-trans-em-2019.pdf

Bento, B. (2011). Na escola se aprende que a diferença faz a diferença. Estudos Feministas, 19(2), 548-559.

Borsoi, I. C. F. (2005). O modo de vida dos novos operários: quando purgatório se torna paraíso. Fortaleza: Editora UFC.

Bourdieu, P. (1998a). A precariedade está hoje por toda a parte. In P. Bourdieu, Contrafogos: táticas para enfrentar a invasão neoliberal (pp. 119-127). Rio de Janeiro: Jorge Zahar.

Bourdieu, P. (1998b). A ilusão biográfica. In M. de M. Ferreira \& J. Amado (Orgs.), Usos e abusos da história oral (pp. 183-191). Rio de Janeiro: Editora da FGV.

Butler, J. (2003). Problemas de gênero: feminismo e subversão da identidade. Rio de Janeiro: Civilização Brasileira.

Castel, R. \& Haroche, C. (2001). Propriété privée, propriété sociale, propriété de soi. Paris : Fayard.

Costa, S. G. \& Ferreira, C. da S. (2006). Diversidade e minorias nos estudos organizacionais brasileiros: presenças e lacunas na última década. Artigo apresentado no Encontro de Estudos Organizacionais, Porto Alegre, RS. Recuperado de http://www.anpad.org.br/admin/pdf/eneo2006-006.pdf

Dardot, P. \& Laval, C. (2015). Uma alternativa ao neoliberalismo (D. P. Andrade e N. K. Ota, Entrevistadores). Tempo Social, 27(1), 275-316.

Dardot, P. \& Laval, C. (2016). A nova razão do mundo: ensaio sobre a sociedade neoliberal. São Paulo: Boitempo.

Dubar, C. (2012). A construção de si pela atividade de trabalho: a socialização profissional (F. Machado trad.). Cadernos de Pesquisa, 42 (146), 351-367.

Duque, T. (2013). Gêneros incríveis: identificação, diferenciação e reconhecimento no ato de passar por. Tese de Doutorado, Universidade Estadual de Campinas, Campinas, SP.

Fontes, V. (2017). Capitalismo em tempos de uberização: do emprego ao trabalho. Marx e o Marxismo, 5(8), 45-67.

Garcia, M. R. V. (2007). "Dragões": gênero, corpo, trabalho e violência na formação da identidade entre travestis de baixa renda. Tese de Doutorado, Universidade de São Paulo, SP.

Goodman, L. A. (1961). Snowball Sampling. Annals of Mathematical Statistics, 32, 148-170.

Green, J. N. (2000). Além do Carnaval: a homossexualidade masculina no Brasil do século XX. São Paulo: Editora da UNESP.

Heloani, J. R. \& Silva, E. P. (2015). Diversidade no trabalho. In P. F. Bendalossi \& J. Borges-Andrade (Orgs.), Dicionário de psicologia do trabalho e das organizações (vol. 1, pp. 303-310). São Paulo: Casa do Psicólogo. 
Irigaray, H. A. R. (2008). A diversidade nas organizações brasileiras: estudo sobre orientação sexual e ambiente de trabalho.

Tese de Doutorado, Fundação Getúlio Vargas, São Paulo.

Irigaray, H. A. R. (2010). Identidades sexuais não-hegemônicas: a inserção dos travestis e transexuais no mundo do trabalho sob a ótica queer. Trabalho apresentado no VI Encontro da Divisão de Estudos Organizacionais da ANPAD, Florianópolis, SC. Recuperado de http://www.anpad.org.br/admin/pdf/eneo425.pdf

Irigaray, H. A. R. \& Freitas, M. E. (2013). Estratégia de sobrevivência dos gays no ambiente de Trabalho. Revista Psicologia Política, 13, 57-74.

Jodelet, D. (2005). Loucuras e representações sociais. Petrópolis, RJ: Vozes.

Juliani, R. P. (2013). Processos de gestão e minorias: um estudo sobre políticas organizacionais de promoção do respeito à diversidade sexual. Trabalho de Conclusão de Curso, Universidade Estadual Paulista Júlio de Mesquita Filho, Jaboticabal.

Juliani, R. P. (2017). LGBTTrabalhadores: trajetórias de vida e representações sociais sobre trabalho. Dissertação de Mestrado, Universidade Federal de São Carlos, São Carlos, SP.

Junqueira, R. D. (2012). Pedagogia do armário e currículo em ação: heteronormatividade, heterossexismo e homofobia no cotidiano escolar. In R. Miskolci \& L. Pelúcio (Orgs.), Discursos fora da ordem: sexualidades, saberes e direitos. São Paulo: Annablume.

Kalleberg, A. L. (2009). O crescimento do trabalho precário. Um desafio global. Revista Brasileira de Ciências Sociais, 24(69), 21-31.

Minayo, M. C. S. (1999). Pesquisa social: teoria, método e criatividade (14⿳亠丷a ed.). Petrópolis, RJ: Vozes.

Nardi, H. C. (2003). A propriedade social como suporte da existência: a crise do individualismo moderno e os modos de subjetivação contemporâneos. Psicologia $\mathcal{E}$ Sociedade, 15(1), 37-56.

Pereira, P. P. G. (2012). Queer nos Trópicos. Apontamentos à margem sobre pós-colonialismos, feminismos e estudos queer. Contemporânea: Revista de Sociologia da UFSCar, 2(2), 371-394.

Rubin, G. (2003). Pensando sobre sexo: notas para uma teoria radical da política da sexualidade. Cadernos Pagu, (21), 1-88.

Salvagni, J. (2011). Risco no trabalho: a formação da identidade dos eletricistas. Século XXI - Revista de Ciências Sociais, 1(2), 32-41.

Saraiva, L. A. S. \& Irigaray, H. A. R. (2009). Políticas de diversidade nas organizações: uma questão de discurso? Revista de administração de empresas, 49(3), 337-348.

Saraiva, L. A. S. (2012). Além dos estigmas profissionais. In M. E. Freitas \& M. Dantas (Orgs.), Diversidade sexual e trabalho (pp. 149-168). São Paulo: Cengage Learning.

Sennett, R. (2009). El Artesano. Barcelona, ES: Anagrama.

Siqueira, M. V. S. \& Zauli-Fellows, A. (2006). Diversidade e identidade gay nas organizações. Trabalho apresentado no Encontro de Estudos Organizacionais, Porto Alegre, RS. Recuperado de http:/www.anpad.org.br/admin/ pdf/2013_EnANPAD_EOR2438.pdf.

Transgender Europe. (2015). Trans Murder Monitoring (TMM) project. Recuperado de http://tgeu.org/tmm-idahotupdate-2015/

Venco, S. (2019). Uberização do trabalho: um fenômeno de tipo novo entre os docentes de São Paulo, Brasil? Cadernos de Saúde Pública, 35 (Suppl. 1), e00207317. Recuperado de https://dx.doi.org/10.1590/0102-311x00207317

Veras, E. F. \& Guasch, O. (2015). A invenção do estigma travesti no Brasil (1970-1980). História, Histórias, 1(5), 39-51.

\section{Endereços para correspondência}

rpjuliani@gmail.com

scopinho@ufscar.br
Recebido em: 04/11/2019

Revisado em: 10/07/2020

Aprovado em: 31/07/2020 